\title{
Positive and negative stroke signs revisited: dissociations between synergies, weakness, and impaired reaching dexterity
}

Alkis. M. Hadjiosif ${ }^{1, *}$, Meret Branscheidt ${ }^{2,4, *}$, Manuel A. Anaya ${ }^{2}$, Keith D. Runnalls ${ }^{2}$, Jennifer Keller ${ }^{5}$, Amy J. Bastian ${ }^{3,5}$, Pablo A. Celnik ${ }^{2}$, John W. Krakauer ${ }^{1,2,3,6}$

${ }^{1}$ Neurology, ${ }^{2}$ Physical Medicine and Rehabilitation, ${ }^{3}$ Neuroscience, Johns Hopkins University, Baltimore, MD; ${ }^{4}$ cereneo Center for Research and Neurorehabilitation, Weggis, Switzerland; ${ }^{5}$ Kennedy Krieger Institute, Baltimore, MD; ${ }^{6}$ Santa Fe Institute, Santa Fe, NM.

${ }^{*}$ These authors contributed equally to this work.

\section{Abstract}

2 Most stroke victims experience motor deficits, usually referred to collectively as hemiparesis. While

3 hemiparesis is one of the most common and clinically recognizable motor abnormalities, it remains under-

4 characterized in terms of its behavioral subcomponents and their interactions. Hemiparesis is comprised of

5 both negative and positive motor signs. Negative signs consist of weakness and loss of motor control

6 (dexterity), whereas positive signs consist of spasticity, abnormal resting posture, and intrusive movement

7 synergies (abnormal muscle co-activations during voluntary movement). How positive and negative signs

8 interact, and whether a common mechanism generates them, remains poorly understood. Here we employed

9 a planar, arm-supported reaching task to assess post-stroke arm dexterity loss, which we compared to the

10 Fugl-Meyer stroke scale; a measure primarily reflecting abnormal synergies. We examined 53 patients with

11 hemiparesis after a first-time ischemic stroke. Reaching kinematics were markedly more impaired in

12 patients with subacute ( $<3$ months) compared to chronic ( $>6$ months) stroke even when matched for Fugl-

13 Meyer score. This suggests a dissociation between abnormal synergies (reflected in the Fugl-Meyer scale)

14 and loss of dexterity, which in turn suggests different underlying mechanisms. Moreover, dynamometry

15 suggested that Fugl-Meyer scores capture weakness as well as abnormal synergies, in line with these two

16 deficits sharing a neural substrate. These findings have two important implications: First, clinical studies 
17 that test for efficacy of rehabilitation interventions should specify which component of hemiparesis they

18 are targeting and how they propose to measure it. Second, there may be an opportunity to design

19 rehabilitation interventions to address specific subcomponents of hemiparesis.

\section{Introduction}

21 Stroke is one of the leading causes of disability globally, with an estimated 13.7 million individuals

22 suffering a stroke each year (Johnson et al. 2019). A large fraction of strokes (up to 70-80\%) results in some

23 degree of motor impairment (Nakayama et al. 1994; Rathore et al. 2002; Parker, Wade, and Hewer 1986),

24 which makes activities of daily living harder, compromising quality of life (Niemi M L et al. 1988; Viitanen

25 et al. 1988). Hemiparesis (or upper motor neuron syndrome) is clinically quite recognizable but remains

26 surprisingly under-characterized in terms of its behavioral components. It has been known since the late

$2719^{\text {th }}$ century that hemiparesis is comprised of loss of ability (negative signs) and an intrusive movement

28 disorder (positive signs) (Hughlings Jackson 1884; Pearce 2004). Negative signs consist of weakness and

29 loss of dexterity or fractionated motor control, whereas positive signs consist of spasticity, abnormal resting

30 postures, and abnormal synergies whereby multiple muscles or joints become co-activated during voluntary

31 movement. How positive and negative signs relate to each other remains poorly understood. Bridging this

32 knowledge gap will be essential for the treatment of hemiparesis, as it will allow us to (a) different

33 components of hemiparesis, allowing clinicians to more reliably track motor recovery after stroke, (b) better

34 isolate and target individual components to make rehabilitation more effective, and (c) better assess the

35 efficacy of rehabilitation interventions.

36 Among positive signs of stroke, abnormal synergies have been the focus of particular attention and widely

37 recognized as a crucial characteristic of motor impairment after stroke. Thomas Twitchell's classic work

38 (Twitchell 1951) describes the time course of recovery of voluntary movement after stroke, from plegia to

39 flexor then extensor synergies to out-of-synergy movements. Given that recovery can get stuck at any point

40 along this sequence, Signe Brunnstrom (Brunnstrom 1966) suggested therapeutic procedures to increase

41 the chance of a patient progressing through it. A scale was subsequently developed to measure and track

42 recovery from synergies - the Fugl-Meyer scale (Fugl-Meyer et al. 1975).

43 The negative signs of stroke are weakness and loss of dexterity or motor control. Dexterity generally refers

44 to the ability to flexibly and independently control muscles and joints to generate the movement repertoire

45 required by a given task. Importantly, the term should not be considered synonymous with or reserved for

46 finger movements. Dexterity might require practice and, after stroke, it can recover independently of

47 weakness (Cortes et al. 2017; Xu et al. 2017). Notably, the intrusion of abnormal synergies might mask

48 dexterity. A previous study showed that when patients with chronic stroke made 3D reaching movements 
49 within synergy, trajectories appeared comparable to those made by healthy controls (Zackowski et al. 2004).

50 In contrast, when these same patients attempted an out-of-synergy reach that required elbow extension, the

51 trajectory was degraded by an intrusive flexor synergy. This intrusion is thought to be invoked in part by

52 the patient needing to lift their arm against gravity, as several studies have shown that external support of

53 the weight of the arm can reduce the effect of abnormal synergies and increase the arm's available

54 workspace (Beer et al. 2007; 2004; Sukal, Ellis, and Dewald 2007). Thus, here we examined the relationship

55 between abnormal synergies and loss of arm dexterity after stroke. To obtain a measure of arm dexterity

56 loss, we quantified kinematics in a planar reaching task. The apparatus provided full support of the weight

57 of the arm, allowing us to assess arm dexterity while minimizing weakness and the intrusion of synergies;

58 moreover, the apparatus constrained the trunk, minimizing the use of compensatory strategies. To measure

59 the extent of abnormal synergies, we used the Fugl-Meyer scale for the upper extremity (FM-UE), which

60 was specifically designed to quantify abnormal synergies post-stroke (Fugl-Meyer et al. 1975; Brunnstrom

61 1966; Twitchell 1951). Because recovery of reaching dexterity and abnormal synergies may have different

62 time courses, we compared them at two different times post-stroke (Bernhardt et al. 2017): during the early

63 and late sub-acute stage (up to 3 months post-stroke) and the chronic stage (at least 6 months post-stroke).

64 We also assessed weakness in a subset of the patients using dynamometry. 


\section{Materials and Methods}

\section{Participants and Ethics Statement}

67 Participants were recruited as part of a multiple-task study of the motor learning, control, and physiology

68 of stroke patients (PaLaS study, Physiology and Learning after Stroke). The study compared these

69 modalities between two stages in recovery: subacute $(<3$ months post-stroke) and chronic $(>6$ months

70 post-stroke). Table 1 shows details for each of the 53 stroke patients ( 27 subacute, 26 chronic) included in

71 this paper, whereas Table 2 shows summary demographics and assessment metrics for the two patient

72 groups and 17 healthy, age-range-matched controls (age comparisons between controls and either patient

73 group, or between patient groups: all $\mathrm{p}>0.3$ ). Recruitment and data collection took place in Johns Hopkins

74 University and the Kennedy Krieger Institute in Baltimore, MD from December 2015 through February

75 2020; participant flow through the study is shown in Figure 1. Patients were recruited from the stroke and

76 rehabilitation units at Johns Hopkins, previous study participants, respondents to advertisement (flyers

77 posted within the hospital), and stroke support groups to which the study was advertised. Healthy controls

78 were recruited through advertisement and among previous study participants. All participants received

79 monetary compensation for their time (\$20/hour). Participants provided informed consent in accordance

80 with the Declaration of Helsinki, whereas procedures were approved by the Johns Hopkins Institutional

81 Review Board.

\section{$82 \quad$ Eligibility criteria}

83 Patients recruited had to be over 21 years old, had suffered an ischemic supratentorial stroke that was their

84 first stroke with motor deficits, exhibited some movement with the affected arm, and be able to provide

85 informed consent and understand the tasks involved. Exclusion criteria relevant to the tasks described in

86 this paper included hemorrhagic transformation or associated intracranial hemorrhage; severe congestive

87 heart failure; unstable angina; uncontrolled hypertension; dementia (assessed based on the Montreal

88 Cognitive Assessment, MoCA (Nasreddine et al. 2005)); severe aphasia or ideomotor apraxia, neglect or

89 hemianopia; and orthopedic or pain issues.

\section{Sessions}

91 Participants underwent two sessions: the main session (T1) and a one-month follow-up (T2). For the

92 subacute group, T1 took place $29.5 \pm 19.8$ days post-stroke (average \pm standard deviation) and T2 took place

$9339.5 \pm 8.5$ days later. For the chronic group, T1 took place 38.6 \pm 29.6 months post-stroke and T2 took place

$94 \quad 39.2 \pm 7.8$ days later. 
medRxiv preprint doi: https://doi.org/10.1101/2021.07.21.21260448; this version posted August 26, 2021. The copyright holder for this preprint (which was not certified by peer review) is the author/funder, who has granted medRxiv a license to display the preprint in perpetuity. All rights reserved. No reuse allowed without permission.

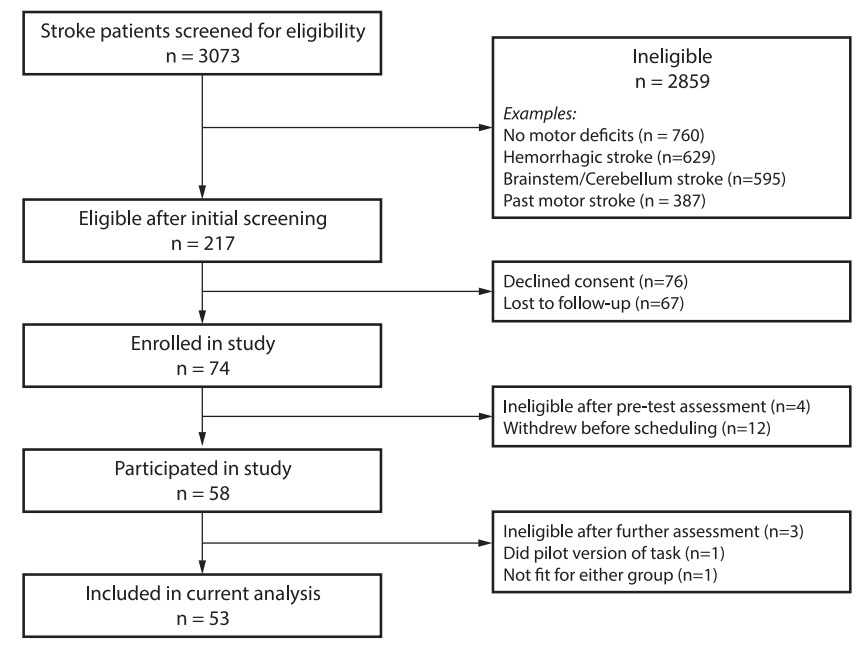

Figure 1: Participant flow through the study. Note that the same patient might fulfill more than one ineligibility criteria.

95 Impairment assessment using the Fugl-Meyer scale for the upper extremity (FM-UE)

96 Assessments were separately scored by at least two different raters (J. Keller, AMH, MB). To obtain the 97 final value, scores were averaged between reviewers (hence some having decimal values). In cases of 98 substantial score differences (3 points or more), assessment videos were again reviewed by both raters 99 together. For the analysis comparing changes in arm dexterity and FM-UE from T1 to T2 (Figure 6), a 100 participant was excluded from the chronic group due to missing FM-UE score. We used the entirety of the 101 score (0-66) for our main analysis. At certain points, as mentioned in our results, we additionally performed 102 comparisons based on subcomponents of FM-UE scores focusing on (a) items referring to movement of the 103 proximal arm (items 3-17 and 31-33 - i.e. everything apart from parts I/VI (reflexes), VII (wrist), and VIII 104 (hand)), (b) items related to within-synergy movements (part II of FM-UE, "Flexor Synergy" items 3-8), 105 or (c) items related to out-of-synergy movements (parts IV and V of the FM-UE: "Movement combining 106 synergies" and "Movement out of synergy").

107 Lesion location

108 A large fraction of our participants (34 out of 53) had clinical MRI images available, which enabled us to 109 compare lesion size between subacute and chronic populations. Lesion size was significantly larger in the 110 chronic participants for which images were available compared to subacute patients $(56794 \pm 21612$ voxels 111 for chronic $(\mathrm{N}=13)$ vs. $8613 \pm 3072$ voxels for subacute $(\mathrm{N}=21), \mathrm{p}=0.047)$, in line with lower FM-UE 112 scores in this group (Table 2). Interestingly, in subacute and chronic patients with mild/moderate FM-UE 113 scores (FM-UE $\geq 26$, on which our main behavioral analysis focused), two populations with relatively 114 matched FM-UE scores ( $46.3 \pm 4.4$ for the 10 chronic vs. $54.4 \pm 2.5$ for the 19 subacute patients with available 115 imaging, $\mathrm{p}=0.17$ ) lesion size was still (marginally) larger in the chronic group (61029 \pm 26714 voxels for 116 chronic $(\mathrm{N}=10)$ vs. $9269 \pm 3364$ voxels for subacute $(\mathrm{N}=19), \mathrm{p}=0.086)$, as shown in Figure 2 . 
medRxiv preprint doi: https://doi.org/10.1101/2021.07.21.21260448; this version posted August 26, 2021. The copyright holder for this preprint (which was not certified by peer review) is the author/funder, who has granted medRxiv a license to display the preprint in perpetuity.

All rights reserved. No reuse allowed without permission.

\section{Reaching Task Details}

118 Participants sat on a robotic chair (Kinarm exoskeleton), which provided arm support while allowing for

119 planar motion (Figure 3). The chair was positioned against a screen that occluded vision of the arm but

120 allowed projection of targets, and a cursor indicating hand position, at arm level. Participants made 10-cm

121 reaching point-to-point movements to eight targets arranged at $45^{\circ}$ intervals about a start position as shown

122 in Figure 3B. Targets and start position were $1 \mathrm{~cm}$ in radius, where the cursor was $0.5 \mathrm{~cm}$ in radius. The start

123 position was defined relative to each participants' shoulder midpoint, and was typically (in 47 out of 53

124 participants) $45 \mathrm{~cm}$ from it but could range from $45-50 \mathrm{~cm}$ to accommodate different sizes and positioning

125 of participants. Upon positioning the cursor on the start position, a cyan target would appear in one of the

126 eight different target positions. Participants were instructed to initiate a movement to the target soon after

127 it appeared. A movement timer would begin as soon as the participant had moved outside the start position.
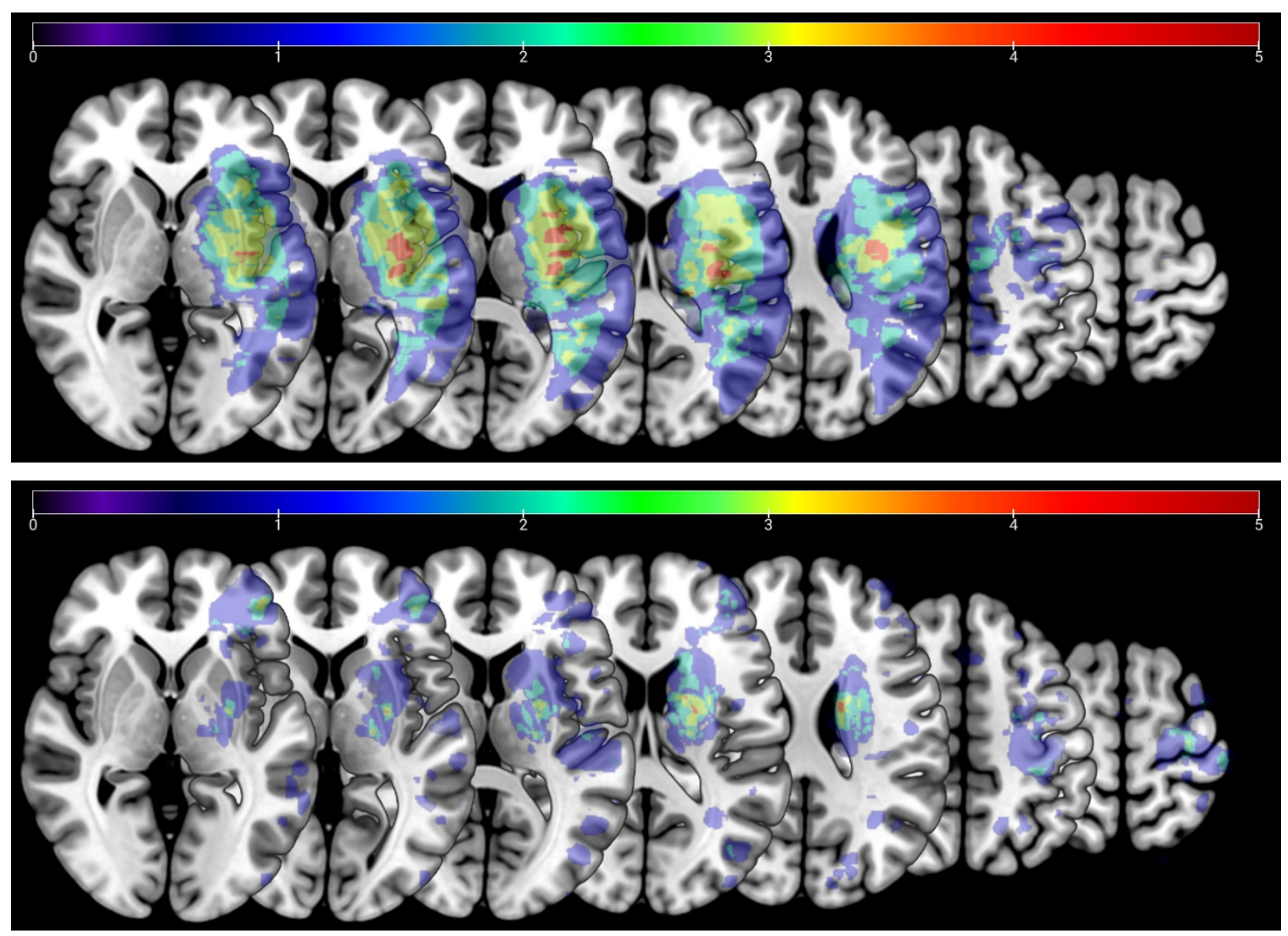

Figure 2: Lesion distribution overlay for chronic (top, $N=10$ ) and subacute (bottom, $N=19$ ) patients with moderate/mild FM-UE impairment (FM-UE $\geq 26$ ). Averaged lesion distribution mapped to JHU-MNI space, with lesion flipped to one hemisphere. Color bar indicates patient count. 
128 The movement would end either when the participant reached the target, or an $800 \mathrm{~ms}$ timer ran out. Upon

129 movement end, the cursor would freeze momentarily and the target would change color based on the

130 participant's speed. Specifically, it would change to orange if the movement terminated on the target but

131 too quickly (movement time $<200 \mathrm{~ms}$ ), or red if the movement failed to reach the target before the $800 \mathrm{~ms}$

132 timer ran out. If the cursor reached the target within the desired $200 \mathrm{~ms}$ to $800 \mathrm{~ms}$ from onset, and was held

133 inside the target for an additional $500 \mathrm{~ms}$, the target would turn green. After an additional $250 \mathrm{~ms}$ wait time,

134 Kinarm would actively return the arm back to the starting position.

135 Participants completed four blocks of 88 movements each (11 to each of the eight different targets),

136 beginning with two blocks with the paretic arm, followed by two blocks with the non-paretic arm. Breaks

137 were given between the blocks as necessary. With the exception of one participant, who did the paretic and

138 non-paretic measurements on different days due to scheduling constraints, the entirety of each session took

139 place on the same day and typically lasted about 45 minutes.

140 Dynamometry

141 We measured strength by dynamometry in 25 of our participants (not all of them as it was only later added

142 to the study assessments). Participants sat on a chair, with their trunk straight and their forearm supported

143 on a table in pronation with the elbow at 90 degrees and the shoulder in an open packed position

144 (approximately 60 degrees of abduction and 30 degrees of horizontal adduction) (Bohannon 1990). Using

145 a handheld dynamometer (MicroFet 2, Hoggan Scientific), we measured the maximum effort of four muscle

146 groups: elbow flexors, elbow extensors, shoulder (horizontal) adductors, and shoulder (horizontal)

147 abductors. The average of two trials were taken for each condition. Both the paretic and non-paretic arms

148 were tested, and strength was expressed as a \% of the force exerted with the non-paretic arm.

149 Data Analysis

150 Analysis was performed using Matlab (Mathworks, Natick MA). Position data were smoothed using an $8^{\text {th }}$ 151 order, $8 \mathrm{~Hz}$ low-pass Butterworth filter, and differentiated to obtain velocity. For the purpose of analysis, 152 we estimated movement onset using a method similar to what described previously in (Cortes et al. 2017):

153 we identified the time of peak speed (first zero-crossing of acceleration that is $>8 \mathrm{~cm} / \mathrm{s}$ ), and then, going 154 backwards, identified movement onset as the time speed surpassed $2 \mathrm{~cm} / \mathrm{s}$. We identified movement end by 155 going forward from the time of peak speed and finding the moment when speed remained $<2 \mathrm{~cm} / \mathrm{s}$ for more 156 than $0.1 \mathrm{~s}$.

157 Data exclusion criteria

158 On occasion, after setting up a participant on the robotic chair, reaching some of the targets was impossible 159 because of mechanical constraints. We thus excluded these targets from our analysis. This case was rare: 
medRxiv preprint doi: https://doi.org/10.1101/2021.07.21.21260448; this version posted August 26, 2021. The copyright holder for this preprint (which was not certified by peer review) is the author/funder, who has granted medRxiv a license to display the preprint in perpetuity.

All rights reserved. No reuse allowed without permission.

160 targets were excluded in only two out of 53 participants. From the remaining trajectories, we excluded

161 movements in which (i) movement direction at peak speed was $\geq 90^{\circ}$ away from target direction, (ii) the

162 participant had not moved beyond 30\% of the target distance (the criteria used in (Cortes et al. 2017) and

163 previously (Kitago et al. 2015)), or (iii) the movement onset analysis described in the previous paragraph

164 failed to provide an estimate of movement onset. For the second training block that we focus on in this

165 manuscript, these criteria excluded a further $3.72 \%$ of patients' movements on the paretic side and $1.30 \%$

166 on the non-paretic side (for healthy controls, the corresponding value was $0.07 \%$ for across both sides).

167 Functional Principal Component Analysis

168 To assess the quality of kinematics, we used functional principal component analysis (fPCA), a method

169 which applies principal component analysis to functional data (Goldsmith and Kitago 2016). This data-

170 driven analysis allows trajectories to be evaluated without prior assumptions about which trajectory features

171 ought to be emphasized. Here, we used fPCA to estimate the Mahalanobis distance of patients' trajectories

172 from the reference population of healthy, age-matched controls. For each patient, we averaged these

173 distances into the average squared Mahalanobis distance $\left(\mathrm{AMD}^{2}\right)$ for sessions $\mathrm{T} 1$ and $\mathrm{T} 2$. Details about this

174 analysis have been reported previously (Goldsmith and Kitago 2016).

175 Estimation of baseline value for $\mathrm{AMD}^{2}$ in controls

176 The functional principal component analysis described above compares patients' trajectories to the

177 population of corresponding trajectories from healthy controls. Because of variability within the reference

178 population itself, $\mathrm{AMD}^{2}$ scores would be nonzero for controls themselves. To estimate an $\mathrm{AMD}^{2}$ value for

179 this baseline, we calculated $\mathrm{AMD}^{2}$ between the trajectories of each control participant compared and the

180 trajectories of all other controls.

181 Statistical comparisons

182 To compare $\mathrm{AMD}^{2}$ between subacute and chronic patients we used unpaired, 2-tailed t-tests without 183 assuming equal variances (Welch's t-test using the Satterthwaite approximation for effective degrees of

184 freedom); p-values reported in Results were based on these tests. In a secondary, non-parametric analysis,

185 we compared these two groups also using a bootstrap procedure (Efron and Tibshirani 1994) using 10,000

186 permutations within each subgroup, which also yielded significant differences between subacute and

187 chronic patients' $\mathrm{AMD}^{2}$.

188 For comparisons within the non-paretic data, we first used an ANOVA to investigate any effect of group

189 (subacute, chronic, controls) since there was no prior expectation either patient group would show reduced

190 reaching dexterity (higher $\mathrm{AMD}^{2}$ ) in the first place. After the ANOVA, we used a Tukey-Kramer test for

191 multiple comparisons for post-hoc tests. 
medRxiv preprint doi: https://doi.org/10.1101/2021.07.21.21260448; this version posted August 26, 2021. The copyright holder for this preprint (which was not certified by peer review) is the author/funder, who has granted medRxiv a license to display the preprint in perpetuity.

All rights reserved. No reuse allowed without permission.

Table 1. Patient characteristics at T1. Showing time since stroke, lesion side, age (non-overlapping 5-year range), gender, Fugl-Meyer Assessment for the Upper Extremity (FM-UE, max. 66); Montreal Cognitive assessment (MoCA, max. 30), and Action Research Arm Test (ARAT, max. 57). 


\begin{tabular}{|c|c|c|c|c|c|c|}
\hline $\begin{array}{l}\text { Time since } \\
\text { stroke }\end{array}$ & Lesion Side & $\begin{array}{c}\text { Age } \\
\text { (5-y range) }\end{array}$ & Gender & MoCa & FM-UE & ARAT \\
\hline \multicolumn{7}{|c|}{$\begin{array}{l}\text { Subacute patients } \\
\qquad \text { (days) }\end{array}$} \\
\hline 29 & $\mathrm{R}$ & $31-35$ & M & 23 & 59 & 55.5 \\
\hline 8 & $\mathrm{~L}$ & $61-65$ & F & 22 & 53 & 39 \\
\hline 17 & $\mathrm{R}$ & $66-70$ & F & 23 & 55 & 57 \\
\hline 15 & $\mathrm{R}$ & $66-70$ & F & 20 & 56 & 45 \\
\hline 12 & $\mathrm{R}$ & $66-70$ & M & 20 & 59 & 45 \\
\hline 30 & $\mathrm{R}$ & $21-25$ & F & 27 & 64 & 57 \\
\hline 57 & $\mathrm{~L}$ & $56-60$ & M & 25 & 33.5 & 36 \\
\hline 17 & $\mathrm{~L}$ & $41-45$ & F & 20 & 53 & 34.5 \\
\hline 8 & $\mathrm{R}$ & $61-65$ & M & 21 & 52.5 & 41 \\
\hline 57 & $\mathrm{~L}$ & $26-30$ & M & 28 & 61.5 & 57 \\
\hline 19 & $\mathrm{~L}$ & $36-40$ & F & 26 & 58 & 54 \\
\hline 47 & $\mathrm{R}$ & $51-55$ & M & 24 & 57 & 56 \\
\hline 9 & $\mathrm{~L}$ & $61-65$ & M & 19 & 56 & 48.5 \\
\hline 12 & $\mathrm{R}$ & $81-85$ & F & 22 & 38 & 37.5 \\
\hline 43 & $\mathrm{R}$ & $71-75$ & F & 27 & 21 & 9 \\
\hline 47 & $\mathrm{R}$ & $61-65$ & F & 30 & 63.5 & 57 \\
\hline 6 & $\mathrm{~L}$ & $61-65$ & $\mathrm{M}$ & 20 & 65 & 57 \\
\hline 55 & $\mathrm{R}$ & $51-55$ & M & 24 & 44 & 37 \\
\hline 21 & $\mathrm{~L}$ & $51-55$ & F & 22 & 64.5 & 57 \\
\hline 19 & $\mathrm{R}$ & $91-95$ & M & 27 & 26 & n.d. \\
\hline 70 & $\mathrm{R}$ & $66-70$ & F & 28 & 59.5 & 56 \\
\hline 47 & $\mathrm{R}$ & $71-75$ & F & 23 & 45 & 54 \\
\hline 14 & $\mathrm{~L}$ & $61-65$ & F & 25 & 61 & 55.5 \\
\hline 17 & $\mathrm{R}$ & $46-50$ & $\mathrm{M}$ & 30 & 62.5 & 57 \\
\hline 12 & $\mathrm{~L}$ & $71-75$ & $\mathrm{~F}$ & 25 & 57.5 & 56.5 \\
\hline 58 & $\mathrm{~L}$ & $46-50$ & $\mathrm{M}$ & 29 & 15 & 11 \\
\hline 51 & $\mathrm{R}$ & $56-60$ & $\mathrm{M}$ & 27 & 11.5 & 3 \\
\hline
\end{tabular}




\begin{tabular}{|c|c|c|c|c|c|c|}
\hline $\begin{array}{c}\text { Time since } \\
\text { stroke }\end{array}$ & Lesion Side & $\begin{array}{c}\text { Age } \\
\text { (5-y range) }\end{array}$ & Gender & MoCa & FM-UE & ARAT \\
\hline \multicolumn{7}{|c|}{$\begin{array}{l}\text { Chronic patients } \\
\text { (months) }\end{array}$} \\
\hline 27 & $\mathrm{R}$ & $26-30$ & F & 30 & 58 & 44.5 \\
\hline 54 & $\mathrm{R}$ & $41-45$ & M & 30 & 13 & 3 \\
\hline 42 & $\mathrm{R}$ & $66-70$ & M & 27 & 60 & 57 \\
\hline 27 & $\mathrm{R}$ & $66-70$ & M & 25 & 13 & 6 \\
\hline 27 & $\mathrm{~L}$ & $56-60$ & M & 25 & 58 & 54.5 \\
\hline 39 & $\mathrm{R}$ & $56-60$ & M & 25 & 47.5 & 44 \\
\hline 24 & $\mathrm{R}$ & $46-50$ & M & 29 & 12 & 3 \\
\hline 76 & $\mathrm{R}$ & $61-65$ & M & 28 & 10 & 7 \\
\hline 11 & $\mathrm{R}$ & $51-55$ & $\mathrm{~F}$ & 23 & 62 & 57 \\
\hline 88 & $\mathrm{R}$ & $61-65$ & F & 25 & 17 & 3 \\
\hline 24 & $\mathrm{R}$ & $56-60$ & M & 20 & 29.5 & 5.5 \\
\hline 8 & $\mathrm{R}$ & $76-80$ & M & 20 & 50 & 43 \\
\hline 59 & $\mathrm{R}$ & $46-50$ & $\mathrm{M}$ & 22 & 24 & 42 \\
\hline 20 & $\mathrm{R}$ & $56-60$ & M & 20 & 17.5 & 3 \\
\hline 72 & $\mathrm{~L}$ & $36-40$ & M & 27 & 60.5 & 55 \\
\hline 58 & $\mathrm{~L}$ & $51-55$ & F & 21 & 9 & 2 \\
\hline 35 & $\mathrm{R}$ & $51-55$ & $\mathrm{M}$ & 26 & 64.5 & 55.5 \\
\hline 7 & $\mathrm{~L}$ & $66-70$ & M & 28 & 64.5 & 57 \\
\hline 7 & $\mathrm{R}$ & $46-50$ & M & 29 & 27 & 14 \\
\hline 8 & $\mathrm{R}$ & $51-55$ & F & 28 & 36 & 14.5 \\
\hline 17 & $\mathrm{R}$ & $56-60$ & F & 26 & 13.5 & n.d. \\
\hline 9 & $\mathrm{R}$ & $41-45$ & $\mathrm{~F}$ & 28 & 33 & 25.5 \\
\hline 7 & $\mathrm{~L}$ & $36-40$ & $\mathrm{M}$ & 26 & 61 & 57 \\
\hline 59 & $\mathrm{R}$ & $56-60$ & $\mathrm{~F}$ & 23 & 18.5 & 3 \\
\hline 95 & $\mathrm{~L}$ & $66-70$ & $\mathrm{~F}$ & 27 & 64 & 57 \\
\hline 103 & $\mathrm{~L}$ & $36-40$ & F & 27 & 48.5 & 52.5 \\
\hline
\end{tabular}


medRxiv preprint doi: https://doi.org/10.1101/2021.07.21.21260448; this version posted August 26, 2021. The copyright holder for this preprint (which was not certified by peer review) is the author/funder, who has granted medRxiv a license to display the preprint in perpetuity.

All rights reserved. No reuse allowed without permission.

\begin{tabular}{|l|c|c|c|}
\hline & $\begin{array}{c}\text { Subacute stroke } \\
\text { patients }\end{array}$ & Chronic stroke patients & Controls \\
\hline N & 27 & 26 & 17 \\
\hline Age & $58.8 \pm 16.3$ & $54.6 \pm 11.5$ & $57.6 \pm 12.4$ \\
\hline Gender & $13 \mathrm{M} / 14 \mathrm{~F}$ & $16 \mathrm{M} / 10 \mathrm{~F}$ & $8 \mathrm{M} / 9 \mathrm{~F}$ \\
\hline Affected Side & $11 \mathrm{R} / 16 \mathrm{~L}$ & $7 \mathrm{R} / 19 \mathrm{~L}$ & $\mathrm{n} / \mathrm{a}$ \\
\hline Handedness & $24 \mathrm{R} / 1 \mathrm{~L} / 2 \mathrm{~A}$ & $24 \mathrm{R} / 2 \mathrm{~L}$ & $15 \mathrm{R} / 1 \mathrm{~L} / 1 \mathrm{~A}$ \\
\hline FM-UE & $50.1 \pm 15.6$ & $37.4 \pm 21.1$ & $66 \pm 0$ \\
\hline ARAT & $45.1 \pm 15.9$ & $30.6 \pm 23.6$ & $57 \pm 0$ \\
\hline MoCA & $24.3 \pm 3.3$ & $25.6 \pm 3.1$ & $27.9 \pm 1.6$ \\
\hline Time Since Stroke & $29.5 \pm 19.8$ days & $38.6 \pm 29.6$ months & $\mathrm{n} / \mathrm{a}$ \\
\hline
\end{tabular}

Table 2. Demographics and clinical characteristics of participants. \pm indicates standard deviation across participants. FM-UE: Fugl-Meyer Assessment for the Upper Extremity; ARAT: Action Research Arm Test; MoCA: Montreal Cognitive assessment. 


\section{Results}

\section{Subacute stroke patients had worse reaching dexterity compared to chronic stroke}

\section{4 patients despite matched Fugl-Meyer scores}

195 To measure quality of reaching movements, we had participants perform $10 \mathrm{~cm}$ point-to-point reaching 196 movements to eight different targets on the 2D plane with arm support, using the Kinarm Exoskeleton 197 (Figure 3). Online visual feedback was provided in the form of a cursor and, with the help of color cues, 198 participants were prompted to reach and stop at the target within 200-800ms after movement onset (for 199 details, see Materials and Methods). In each session, a total of 176 movements were performed with each 200 hand (two blocks of 11 reaches to each of the eight targets, with paretic-arm blocks performed first).

A

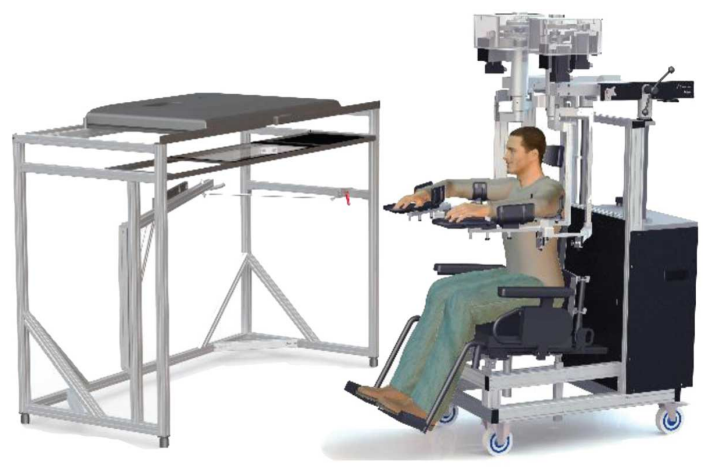

B

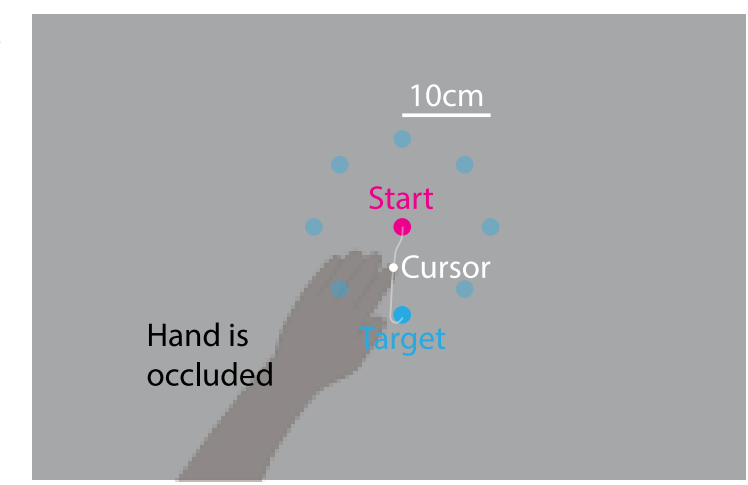

Figure 3. Task design and example trajectories.: Illustration of the experimental apparatus (Kinarm, BKIN Technologies, Kingston, Ontario, figure adapted from (Tyryshkin et al. 2014). B: The task: participants had to make point-to-point outwards reaching movements to 8 different targets (cyan) beginning from a starting position (pink). Vision of the hand was occluded; instead, during movement, a cursor was displayed on screen on the plane of the arm.

201 To avoid familiarization effects (see Figure S1), we focused our analysis on the second block (88 202 movements). Examples of participants' trajectories with the paretic arm are shown in Figure 4A. We made 203 two primary observations. First, subacute participants had markedly worse trajectories compared to chronic 204 participants even when matched for FM-UE scores. Second, there was convergence onto the shape of 205 trajectories of the control population as patients' FM-UE scores improved.

206 To formally assess reaching trajectories in stroke patients and generate a scalar comparison metric, we used 207 functional principal component analysis (fPCA), a method which compares patients' movement trajectories 208 to those of a reference population (Kitago et al. 2015; Goldsmith and Kitago 2016; Cortes et al. 2017). In 209 this study, our reference population consisted of a group of 17 age-matched controls (see Table 2). 210 Specifically, fPCA assigns a score to each trajectory produced by the patient, based on how that trajectory's 
211 shape differs from the average control trajectory, given the natural variability of control trajectories (for

212 more details see Materials and Methods). This resulting score is a Mahalanobis distance (MD), and can be

213 understood as a generalization of the $\mathrm{z}$-score; it is large when the movement is impaired (i.e. it is dissimilar

214 to the healthy controls used as a reference) and small when the movement is similar to healthy controls.

215 This analysis avoids having to assess many different kinematic variables (e.g. angular error, accuracy, jerk,

216 curvature), and then not knowing how to interpret them when they dissociate (Kitago et al. 2015; Krakauer

217 and Carmichael 2017). As a measure of reaching dexterity for each participant, we calculated these MDs

218 across trials and target directions. We refer to the resultant measure as the Average Squared Mahalanobis

219 distance $\left(\mathrm{AMD}^{2}\right)$ (Cortes et al. 2017).

220 Because $\mathrm{AMD}^{2}$ estimates the dissimilarity of each trajectory from the average trajectory in the reference 221 population, it will be non-zero even for unimpaired trajectories given the natural variability of movement.

222 Hence, we estimated a baseline value for $\mathrm{AMD}^{2}$, denoted by how low the $\mathrm{AMD}^{2}$ score would be for 223 unimpaired performance, by taking each control participant's trajectories and computing their AMD $^{2}$ 224 against the trajectories of remaining controls, which yielded an average $\mathrm{AMD}^{2}$ of $8.13 \pm 0.58$ (mean $\pm \mathrm{SEM}$ 225 across control participants).

226 Consistent with the trajectory shapes shown in Figure 4A, AMD ${ }^{2}$ scores indicated impaired trajectory 227 kinematics for stroke patients compared to controls (average \pm SEM AMD $^{2}$ for all patients: $61.4 \pm 7.5$; for all 228 controls: $8.13 \pm 0.58$ ). Interestingly, however, subacute patients tended to show markedly worse kinematics 229 than chronic patients despite similar or higher FM-UE scores, as illustrated in Figure 4B. Because very few 230 participants in the subacute stage had low FM-UE scores, resulting in a higher average FM-UE for the 231 subacute group compared to the chronic group (on average, FM-UE of 50.1 \pm 3.0 for the subacute vs. $23237.4 \pm 4.1$ for the chronic group, see Figure 4B), we performed additional analysis on participants with 233 moderate and mild impairment (FM-UE $\geq 26$, the cut-off is based on previous work (P. W. Duncan, Lai, and 234 Keighley 2000; Krakauer and Carmichael 2017)). For these patients (24 subacute and 16 chronic), despite 235 matched FM-UE (54.3 \pm 2.1 for the subacute vs. 51.5 \pm 3.3 , mean \pm SEM for the chronic patients, respectively, $236 \mathrm{p}=0.47$ ), trajectory abnormalities were substantially greater in the subacute group (AMD ${ }^{2}$ of $60.6 \pm 10.4$ 237 vs. $21.5 \pm 4.2, p=0.0016$, Figure 5$)$. These two groups were significantly different $(\mathrm{p}=0.0028)$ even when 238 the subacute participant with the highest $\operatorname{AMD}^{2}$ (174.9, Figure 5, right) was excluded as potential outlier; 239 they were also clearly different in a secondary, non-parametric analysis using bootstrap (Figure S2). We 240 also considered whether this $\mathrm{AMD}^{2}$ difference between subacute and chronic patients could be due to FM241 UE capturing different types of abnormality in each group. In other words, in spite of similar overall FM242 UE scores, could there be systematic differences in subcomponents of the FM-UE between subacute and 243 chronic patients? We thus isolated and compared (a) the part of the FM-UE focusing on movement of the 

movement between these two subgroups (subacute vs. chronic mild/moderate patients). We found no significant differences (proximal part: $30.8 \pm 1.0$ vs. $29.7 \pm 1.6$ for subacute vs. chronic, $\mathrm{p}=0.57$; out-ofsynergy part: $10.2 \pm 0.5$ vs. $9.7 \pm 0.8$ for subacute vs. chronic, $\mathrm{p}=0.60)$, ruling out that $\mathrm{AMD}^{2}$ differences could be explained by differences in the distribution of abnormality within the FM-UE for each group.

A

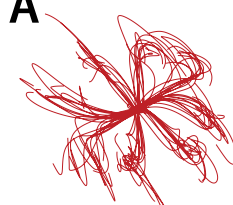

a
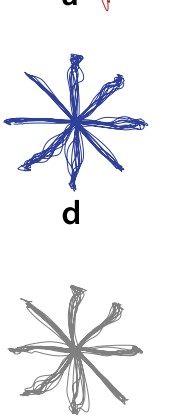

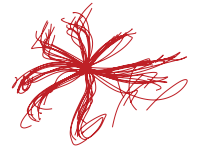

b

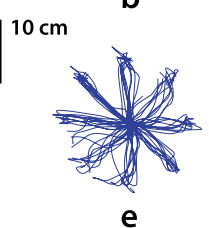

e

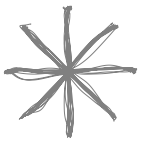

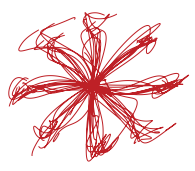

C
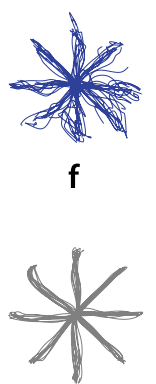

B

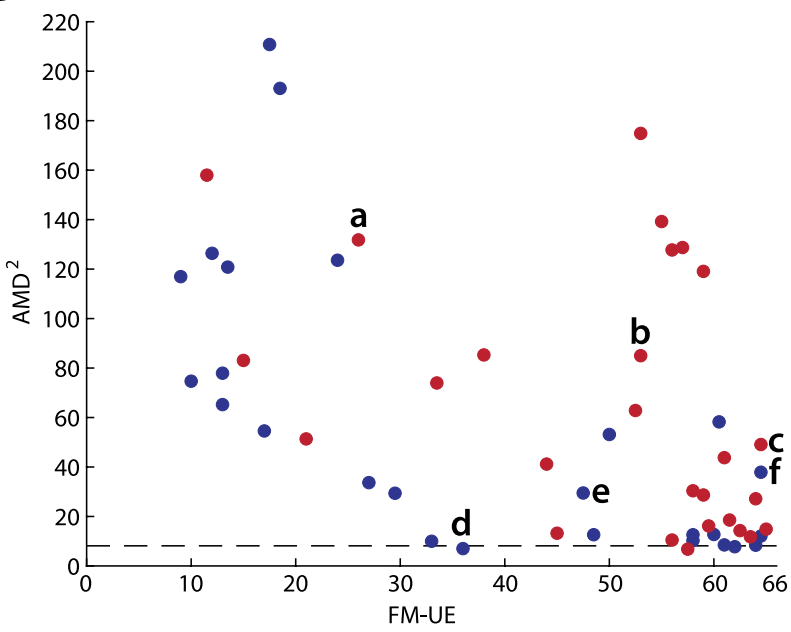

Figure 4. Subacute patients had worse kinematics compared to chronic patients for similar Fugl-Meyer scores. A: Exemplar movement trajectories, using the paretic arm, for three subacute patients (red), three chronic patients (blue), and three controls (gray). B: Scatter plot of kinematic abnormality $\left(A M D^{2}\right)$ vs. FMUE for the subacute (red) and chronic (blue) groups. Note the higher $A M D^{2}$ for subacute patients, especially the ones with moderately and mildly impaired FM-UE $(\geq 26)$. The lowercase letters (a-f) point to the corresponding trajectories on the panel $\boldsymbol{A}$. The black dashed line indicates baseline calculated based on control data.

The difference in arm dexterity in spite of matched FM-UE that we observed, suggests that impaired arm dexterity (a negative sign) is dissociable from abnormal synergies (a positive sign on which FM-UE is based) - one is not causing the other. This failure on part of the FM-UE to capture differences in the quality

252 of motor control during the subacute recovery stage further suggests that additional assessments may be 253 needed to capture the full spectrum of the post-stroke motor control phenotype; and/or recovery of motor 254 control within the subacute stage may lag behind corresponding improvements in FM-UE.

255 In addition to failing to capture motor control differences between the subacute and chronic groups, the 256 FM-UE was a relatively poor predictor of kinematic deficits overall: while FM-UE accounted for a small 257 fraction of the differences in $\mathrm{AMD}^{2}$ scores across the entire patient population $\left(\mathrm{R}^{2}=0.27, \mathrm{p}=0.00007\right)$, 258 this relationship appeared mostly driven by chronic patients with greater impairment $(\mathrm{FM}-\mathrm{UE}<26)$ and 

only patients with mild/moderate impairment [FM-UE $\geq 26]$ were examined, $\left.R^{2}=0.04, p=0.24\right)$. However, very low FM-UE scores could be attributable to damage that is extensive enough to separately lead to both an abnormal synergy and loss of dexterity, without meaning that loss of dexterity was specifically due to the abnormal synergy. Moreover, very low FM-UE scores imply substantial abnormality even for withinsynergy movements, reducing the metric's specificity as an indicator of the strength of abnormal synergies.
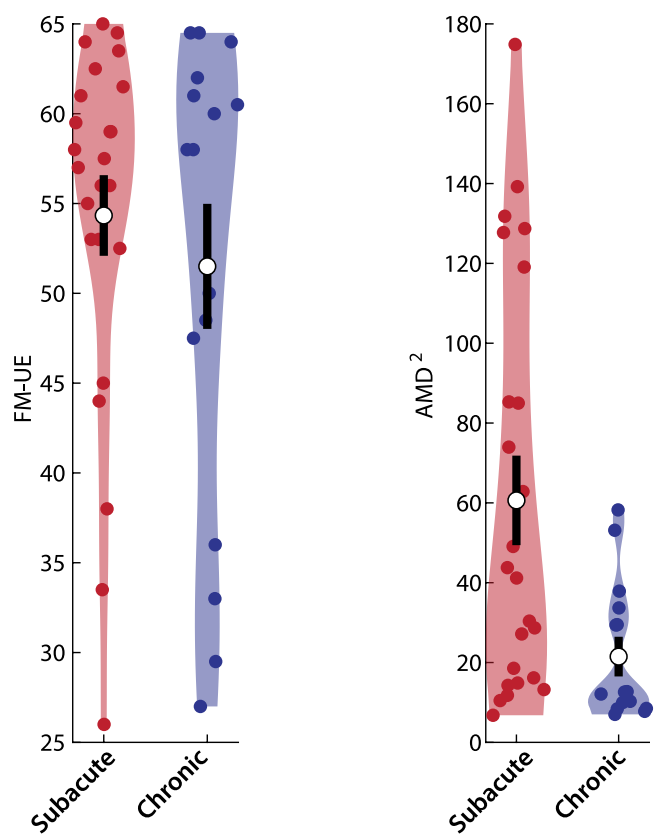

\section{Figure 5. Subacute patients have worse kinematics compared to chronic patients in spite of matched} Fugl-Meyer scores. Violin plots of the average FM-UE (left) and $A M D^{2}$ (right) for chronic and subacute patients with moderate/mild (FM-UE $\geq 26$ ) impairment. Note how, for this FM range, where both subacute and chronic patients were adequately represented, we found much worse motor control (higher $A M D^{2}$ ) for subacute patients compared chronic patients, despite matched FM-UE. White circles indicate mean values and thick black lines indicate mean \pm SEM.

If the differences in kinematics between subacute and chronic patients matched for FM-UE were indeed due to time post-stroke, we would expect that, given time, the kinematics/FM-UE relationship for the subacute group would generally converge towards the kinematics/FM-UE relationship seen in the chronic group. To examine this, we tested for changes in both FM-UE and $\mathrm{AMD}^{2}$ in the subset of patients who completed the one-month follow-up (T2) session, and had been classified as moderate/high FMS ( $\geq 26$ )

273 during the main (T1) session -14 patients in each group. We saw that, indeed, the relationship between $274 \mathrm{AMD}^{2}$ and FM-UE in the subacute group in the one-month follow-up (T2 session) tended to approach the 275 relationship observed for chronic patients, with the most kinematically impaired subacute patients 276 drastically reducing their $\mathrm{AMD}^{2}$ (illustrated by the long downward-facing red arrows in Figure 6A). On 277 average, subacute patients improved both their FM-UE (59.6 \pm 1.1 vs. 63.2 $\pm 0.7, \mathrm{p}=0.0010)$ and their 278 kinematics $\left(\mathrm{AMD}^{2}\right.$ of $61.8 \pm 15.1$ vs. $\left.29.7 \pm 5.1, \mathrm{p}=0.023\right)$. Changes in $\mathrm{AMD}^{2}$ between $\mathrm{T} 1$ and $\mathrm{T} 2$ might 
appear statistically weaker when tested using parametric tests due to lack of normality in the distribution of $\mathrm{AMD}^{2}$; a non-parametric comparison using bootstrap suggested a more clear difference $(\mathrm{p}=0.0008)$. In

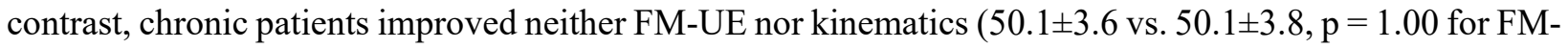
$\mathrm{UE}$ and $23.4 \pm 4.6$ vs. $21.2 \pm 4.7, \mathrm{p}=0.64$ for $\mathrm{AMD}^{2}$ [p $=0.29$ using bootstrap]), as illustrated in Figure $6 \mathrm{~B}$. We note that the lack of improvement in kinematics for the chronic group suggests no effect of savings or additional practice in the point-to-point reaching task (aside from a familiarization effect, illustrated in Figure S1), meaning that the changes in $\mathrm{AMD}^{2}$ we see in the subacute group represent improvements in reaching dexterity rather than motor learning.
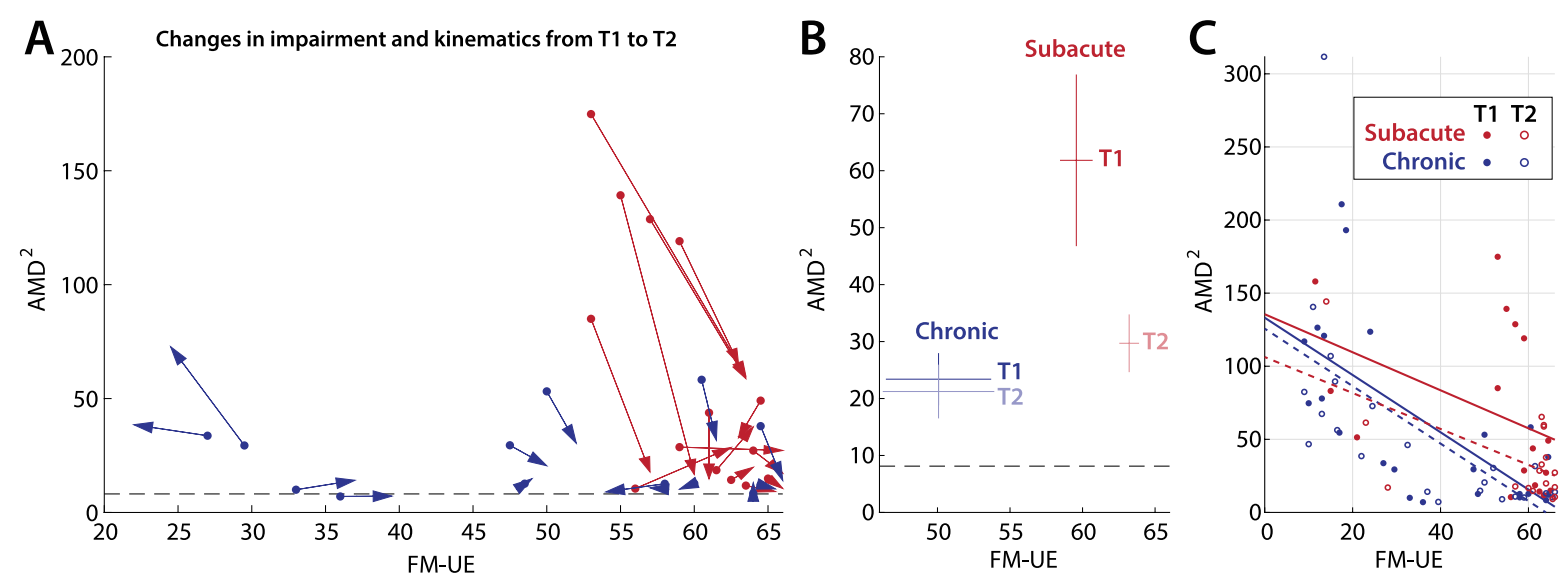

Figure 6. Changes in kinematics and FM-UE as recovery progresses. A: Individual changes in kinematic abnormalities $\left(A M D^{2}\right)$ and FM-UE between the main session (T1, dots) and the one-month follow-up (T2, tip of arrowpoints). B: Subject averages for these two groups. Errorbars indicate SEM. In both A and B, patients were only included if (a) they completed both T1 and T2 sessions, and (b) were classified in the moderate/mild group during T1. C: Linear fits of the FM-UE vs. AMD relationship for both subacute and chronic groups for both $T 1$ and T2. In T2, the FM-UE / AMD for the subacute group becomes more similar to the chronic group.

287 In addition, we compared data from participants which completed both the T1 and T2 sessions regardless 288 of FM-UE (a total of 17 subacute and 23 chronic) and investigated whether a stronger AMD $^{2} / F_{M}-U E$ 289 relationship emerges among subacute patients in T2 compared to T1. Indeed, subacute participants showed 290 a tighter FM vs. $\mathrm{AMD}^{2}$ relationship in $\mathrm{T} 2\left(\mathrm{R}^{2}=0.38, \mathrm{p}=0.0089\right)$ compared to $\mathrm{T} 1\left(\mathrm{R}^{2}=0.17, \mathrm{p}=0.10\right)$, 291 more similar to the strength of the same relationship for chronic participants, which was strong in both $\mathrm{T} 2$ $292\left(\mathrm{R}^{2}=0.38, \mathrm{p}=0.0016\right)$ and $\mathrm{T} 1\left(\mathrm{R}^{2}=0.45, \mathrm{p}=0.00042\right)$, as shown in Figure 6C. This provides further evidence 293 that the differences we observed between subacute and chronic groups in T1 were indeed due to time after 294 stroke. 
medRxiv preprint doi: https://doi.org/10.1101/2021.07.21.21260448; this version posted August 26, 2021. The copyright holder for this preprint (which was not certified by peer review) is the author/funder, who has granted medRxiv a license to display the preprint in perpetuity.

All rights reserved. No reuse allowed without permission.

Motor control deficits in the non-paretic arm were worse in the subacute compared to the chronic period

297 Finally, we analyzed trajectories in the non-paretic arm. While less pronounced than deficits in the paretic arm, both subacute and chronic patients had higher non-paretic $\mathrm{AMD}^{2}$ scores compared to controls (20.80 \pm 3.74 and $14.68 \pm 1.48$ vs. $8.12 \pm 0.58$ for the subacute, chronic, and controls, respectively, see Figure 7). An ANOVA revealed a significant effect of group $(\mathrm{p}=0.0094)$. Post-hoc analyses showed that subacute patients had significantly greater $\mathrm{AMD}^{2}$ compared to controls $(\mathrm{p}=0.0070)$ but not compared to chronic patients $(\mathrm{p}=0.21)$. While chronic patients showed higher $\mathrm{AMD}^{2}$ than controls, this difference was not significant either $(\mathrm{p}=0.25)$-p-values obtained using the Tukey-Kramer test for multiple comparisons. This shows a clear deficit in motor control of the non-paretic arm at least early after stroke, mirroring previous results demonstrating reaching deficits in the non-paretic arm (Winstein and Pohl 1995; Haaland et al. 2004; Cortes et al. 2017). This finding suggests that loss of reaching dexterity after stroke is not restricted to the contralesional side, and may be captured by high-sensitivity assays like our simple reaching task and associated fPCA analysis.

A
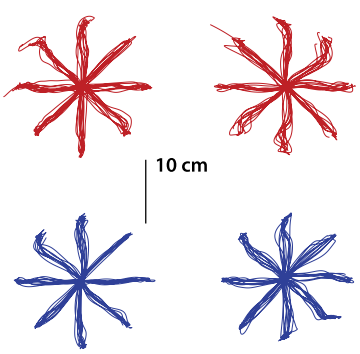

1

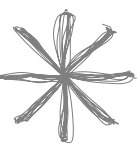

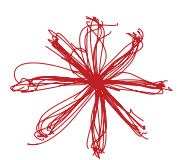
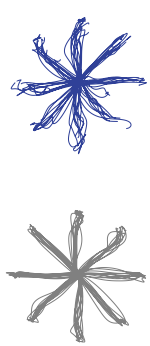

B ${ }_{120}$

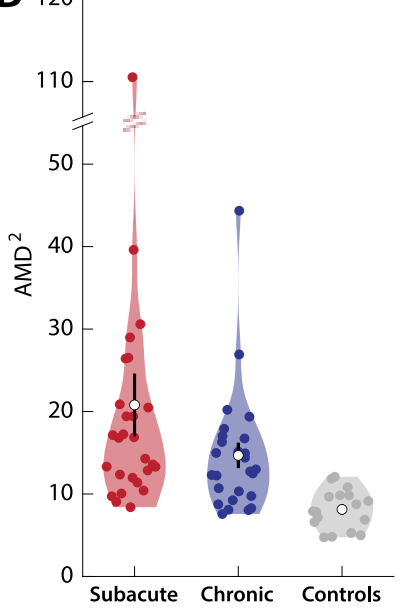

Figure 7. Kinematic abnormalities in the non-paretic arm. Subacute participants showed worse kinematics (higher $A M D^{2}$ ) with their non-paretic arm compared to chronic participants and controls. A: example trajectories (same participants as in Figure 3B); B: Violin plots of the $A M D^{2}$ for each group. White circles indicate mean values, thick black lines indicate mean \pm SEM.

311 Our findings suggest a dissociation between abnormal synergies, assessed through the FM-UE scale, and 312 arm dexterity, assessed through kinematics. However, while FM-UE is a synergy-based measure, it may 313 also reflect weakness - for example, we have previously found a strong correspondence between FM-UE 314 improvement and recovery of strength (Cortes et al. 2017). Could the FM-UE vs. dexterity dissociation in 315 our data instead reflect a strength/dexterity dissociation, as has been shown in earlier work (Ada et al. 316 1996)? 
medRxiv preprint doi: https://doi.org/10.1101/2021.07.21.21260448; this version posted August 26, 2021. The copyright holder for this preprint (which was not certified by peer review) is the author/funder, who has granted medRxiv a license to display the preprint in perpetuity.

All rights reserved. No reuse allowed without permission.

317 To assess the contribution of strength to our findings, we measured patients' horizontal shoulder adduction/

318 abduction and elbow flexion/ extension strength. As dynamometry was only later added to the study

319 assessments, it was not performed in all participants. In a subset of 17 participants (11 subacute and six

320 chronic) plus an additional eight of our early participants (who were enrolled in a different study and were

321 all at the chronic stage at the time of the measurement), we examined the relationship between FM-UE

322 scores and strength at each joint (total of 25 participants). With the exception of horizontal shoulder

323 adduction, strength correlated with FM-UE (see Figure 8). In particular, not only elbow extension strongly

324 correlated with FM-UE $\left(\mathrm{R}^{2}=0.68, \mathrm{p}=4 \times 10^{-7}\right)$, but elbow flexion also did $\left(\mathrm{R}^{2}=0.39, \mathrm{p}=0.0009\right)$. The

325 latter relationship was present even when we examined only the FM items strictly related to out-of-synergy

326 movements (out-of-synergy FM-UE vs. elbow flexor strength: $\mathrm{R}^{2}=0.35, \mathrm{p}=0.0019$ ). As elbow flexor

327 strength correlated almost as well as elbow extensor strength did to the part of FM-UE that evaluates

328 movements out of flexor synergy, we find it unlikely that strength increases at the elbow are the cause of

329 the ability to move out of synergy; rather, the correlations suggest a recovery process that is common for

330 strength and synergies. We also found that elbow extensor strength correlated - even better than elbow

331 flexor strength did - to the part of FM-UE that evaluates movements within flexor synergy $\left(\mathrm{R}^{2}=0.51, \mathrm{p}=\right.$

332 0.00007). Similarly, we find it unlikely that increased extension strength is the cause of the ability to move

333 within flexor synergy; instead suggesting a common recovery process.

334 These findings indicate that there is indeed a dissociation between synergy and arm dexterity rather than

335 only a dissociation between strength and arm dexterity. Importantly, previous work has shown a strong

336 correlation between FM-UE and measures of synergy abnormality measured through EMG (Bourbonnais

337 et al. 1989; Dewald et al. 1995). This reinforces our conclusion that the findings here substantially reflect

338 a dissociation between the presence of synergies and loss of dexterity. Future work may corroborate this

339 using EMG, for example. 

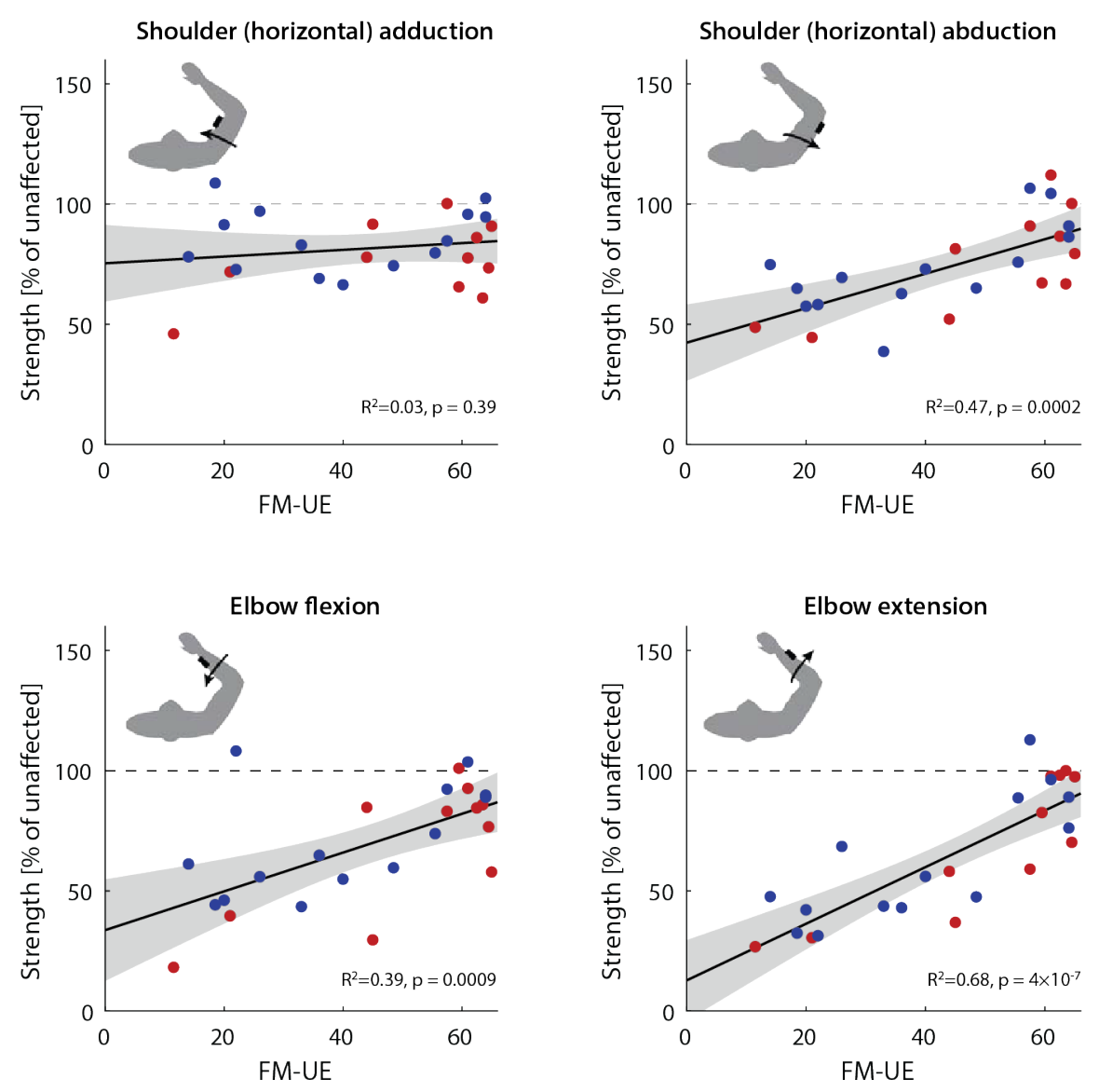

Figure 8. Relationship of weakness and FM-UE. Comparing strength (expressed as a \% of non-paretic strength) with each patients' FM-UE scores revealed strong correlations between FM-UE and shoulder abduction strength, elbow flexion strength, and elbow extension strength, but not shoulder adduction strength (which was relatively high across the whole patient population). For each panel, each dot represents a patient (red: subacute; blue: chronic, at the time of examination), whereas the solid black line indicates linear fit across all patients (with shaded area indicating the corresponding confidence interval). 


\section{Discussion}

\section{Significance of our findings for assessing post-stroke motor impairment}

342 Here we sought to dissect the hemiparesis phenotype into its constituent components. Given the prevalence

343 and impact of hemiparesis, it is important to assess specific post-stroke motor impairments with quantitative

344 metrics to enable clinicians to reliably characterize the initial deficit, and to predict and track recovery. This

345 knowledge may help optimize rehabilitation (P. W. Duncan et al. 1992; C. Stinear 2010; C. M. Stinear et

346 al. 2017) and also enable researchers to compare the effectiveness of different experimental treatments and

347 interventions to enhance recovery. The FM is widely used in tracking post-stroke motor recovery, in fact it

348 is the de facto impairment measure from the ICF used for studies and trials (Cortes et al. 2017; P. W.

349 Duncan et al. 1992; Rabadi and Rabadi 2006; Chollet et al. 2011; Crisostomo et al. 1988; Francisco et al.

350 1998; Kwakkel et al. 2016; Van der Lee et al. 1999; Fasoli et al. 2003; Lo et al. 2010; Lum et al. 2002; P.

351 Duncan et al. 2003; Feys Hilde M. et al. 1998). Here, however, we have shown that FM-UE might miss one

352 of the components of hemiparesis - reaching dexterity loss - even though it might well capture weakness

353 and abnormal synergies. Our findings, showing a poor correspondence between these two types of

354 impairment, suggest the need for more careful matching between the rehabilitation intervention being tested

355 in clinical studies and the chosen primary outcome measure: hemiparesis - or upper motor neuron syndrome

$356-$ is too vague a term as it lumps weakness, synergies, and dexterity loss.

357 Why would FM-UE not be that suitable for assessing reaching dexterity deficits? Recent work has shown 358 that reaching dexterity in stroke patients is improved with weight support; conversely, without weight 359 support dexterity might be masked by weakness and abnormal synergies. Beer and colleagues (Beer et al. 360 2004) found that external arm support allowed for significantly greater peak torques when moving to distal 361 targets requiring elbow extension and/or shoulder flexion, i.e. arm support facilitated movements that 362 required breaking out of flexor synergy. At the same time, there was little, if any, effect of external arm 363 support for movements to proximal targets, that involved elbow flexion and shoulder extension. A 364 subsequent study by the same group also found that, while providing arm support allows for greater range 365 and speed of elbow extension (Beer et al. 2007), this improvement was independent of reduced shoulder 366 strength or elbow flexor/extensor strength imbalance. This suggested that abnormal synergies - and not 367 merely weakness per se - were the sign alleviated by arm support. This finding mirrored earlier results for 368 3D movements (Zackowski et al. 2004), which showed a critical effect of synergy intrusion in the absence 369 of weight support. Thus, tasks which require the patient to make multi-joint movements in 3D without 370 support, like most of the test components of the FM-UE, will primarily reflect weakness and synergies, 371 masking residual dexterity. 
medRxiv preprint doi: https://doi.org/10.1101/2021.07.21.21260448; this version posted August 26, 2021. The copyright holder for this preprint (which was not certified by peer review) is the author/funder, who has granted medRxiv a license to display the preprint in perpetuity.

\section{Potential mechanisms behind differences in motor control between the subacute and}

\section{3 chronic patients}

374 Here, our data showed a clear dissociation between the FM-UE score and the quality of planar reaches. It

375 still needs to be explained, however, why the dissociation took the specific form it did: it is not merely that 376 FM scores are poor predictors of the quality of reaching, but there was a clear bias whereby planar reaches 377 were substantially worse in the subacute as compared to the chronic group in patients with matched FM378 UE scores. A potential explanation for this discrepancy may be that the residual corticospinal tract needs 379 time and practice to reach its maximal level of potential performance. Thus, improvements in negative signs 380 might lag improvements in positive ones. This explanation, however, appears to contradict our previous 381 work showing that recovery of planar kinematics occurs over the first five weeks post-stroke and then 382 plateaus (Cortes et al. 2017). We considered the potential explanation that at least some of the patients in 383 the sub-acute group were still within this five-week window and therefore had not yet reached their full 384 recovery. We reasoned that this could still be the case despite the fact that, overall, this group would be less 385 impaired than the chronic group with respect to the FM-UE because they have matched scores and yet could 386 only be expected to improve further. Indeed, the sub-acute patients with the highest $\mathrm{AMD}^{2}$ scores on T1 387 tended to improve drastically on T2, as illustrated in Figure 6A.

\section{The Fugl-Meyer assessment, abnormal synergies and weakness}

389 In this study, we relied on FM-UE as a measure of abnormalities in muscle synergy. As we mention in the 390 introduction, FM-UE was designed to capture the stages of post-stroke recovery described by (Twitchell 391 1951) and (Brunnstrom 1966), a prominent feature of which is the intrusion of abnormal synergies. In turn, 392 this made the scale a strong indicator of synergy abnormality. In line with this idea, the degree of synergy 393 abnormality assessed through EMG was found to strongly (negatively) correlate with FM-UE scores across

394 patients (Bourbonnais et al. 1989; Dewald et al. 1995). Nevertheless, future studies could corroborate our 395 findings with EMG.

396 In addition, here we also found that FM-UE scores also correlate with weakness, in line with our previous 397 work suggesting that FM-UE recovery mirrors strength recovery (Cortes et al. 2017). This relationship was 398 present not only for elbow extension strength but also for elbow flexion strength (Figure 8); it would be 399 unlikely to have a causal relationship between increased flexion strength and ability to move out of flexor 400 synergy. This observation is consistent with previous findings in which increased extensor reach was 401 observed when arm support was given: externally-provided arm support is orthogonal to extensor (or flexor) 402 strength (Sukal, Ellis, and Dewald 2007). Instead, ours and previous findings suggest that the FM-UE / 403 weakness correlation might indicate a shared substrate between abnormal synergies and weakness. 
The shared substrate hypothesis would fit with observations that abnormal synergies are mitigated when weakness is itself mitigated through arm support (Beer et al. 2004; 2007; Sukal, Ellis, and Dewald 2007). A potential explanation is that damage to the (contralateral) corticospinal tract (CST) after stroke may lead to increased reliance on the (ipsilateral) reticulospinal tract (RST), providing some strength at the expense

408 of abnormal synergies (McPherson et al. 2018). In support of this theory, it was shown that corticospinal

409 lesions in macaques led to increased responsivity in reticulospinal pathways which innervated forearm

410 flexor muscles (Zaaimi et al. 2012); moreover it was recently shown that strength training in monkeys

411 involves adaptations in the reticulospinal, but not the corticospinal tract (Glover and Baker 2020). This

412 previous work, together with our findings, thus suggests an anatomical and physiological dissociation

413 (corticospinal vs. reticulospinal) that may map onto the behavioral dissociation (positive vs. negative signs).

414 This theory, however, raises an apparent paradox: if upregulation of the RST increases both strength and

415 abnormal synergies, then how do patients proceed to recover from synergies without concomitant loss of

416 strength? There are a few possible non-mutually exclusive answers to this question that relate to recovery

417 of CST function. First, as the CST becomes able to provide some strength, reliance on the RST may be

418 reduced. Second, the RST might be unable to provide strength for some muscles, which instead may rely

419 on CST recovery: for example, CST integrity may be necessary for strength in the FDI, a distal muscle but

420 not the biceps (Schambra et al. 2019). Studies in monkeys using spike-triggered averaging have found that

421 ipsilateral RST projections led to facilitation in the biceps but suppression in the triceps (Davidson and

422 Buford 2004; Davidson, Schieber, and Buford 2007); thus, the (contralateral) CST - which can facilitate

423 either flexors or extensors (Cheney, Fetz, and Mewes 1991)- may be necessary for control of extensor

424 muscles, which is needed to break out of the flexor synergy. Third, given that both CST and RST converge

425 upon spinal interneurons (Riddle, Edgley, and Baker 2009; Riddle and Baker 2010), the CST might directly

426 regulate RST (Schepens and Drew 2006). Thus, CST recovery may restore its regulatory effect upon the

427 RST, reducing abnormal synergies but maintaining strength.

\section{Limitations}

429 Our comparison of kinematics between subacute and chronic groups focused on patients with moderate and 430 mild impairment based on their FM-UE score. This was due to the very low number of subacute participants 431 with low FM-UE scores, which prevented reliable comparisons with the corresponding part of the chronic 432 group: we were able to recruit only 3 subacute patients with a FM-UE of $<26$ compared to 10 chronic 433 patients in the same subgroup. We interpret this difference as the result of the difficulty of recruiting patients 434 in the subacute stage after stroke. Both eligible subacute and chronic patients were recruited irrespective of 435 their FM-UE score (within the 10-64 range). However, a subacute patient with high impairment will be 436 likely to spend more time in the hospital and in rehabilitation, thus less likely to have time on research 
437 participation before the subacute time window expires. Moreover, increased impairment itself might make

438 them less likely to be interested in joining in the first place, given that they may need more time to adjust.

439 Hence, our observation in this study and others is that subacute patients who are able and eager to participate

440 will tend to be less impaired in the first place.

441 However, we would not expect that the difference in kinematics between the subacute and chronic groups 442 seen for moderate- and mild-impairment patients would also manifest in highly impaired patients. First, 443 patients with high impairment would show difficulty with kinematics regardless of their recovery stage: 444 lower and lower FM-UE scores would amount to impairment closer and closer to complete lack of 445 movement. For example, a plegic patient would have a FM-UE score very close to zero, and being unable 446 to move at all, they would have a complete deficit in their kinematics in our task, regardless of time after 447 stroke. Second, the very fact that the FM-UE score failed to capture a good part of motor control deficits, 448 specifically during the subacute stage, paired with the assumption that the subacute patients who 449 participated may have had less overall impairment, suggests that subacute patients with low FM-UE may 450 tend to fare better in components of impairment not well-captured by the FM-UE (one of which is motor 451 control). Finally, there seems to be a difference how severe vs. moderate/mild patients recover: in contrast 452 to moderate/mild patients, a fraction of severe patients may not recover much at all, and thus show less 453 improvement as they advance to the chronic stage (Nakayama et al. 1994; Jørgensen et al. 1995; Krakauer 454 and Carmichael 2017). While this observation was derived by comparing more general impairment scales 455 (and FM-UE itself), it might also hold for movement kinematics as well.

456 We also note two more limitations. First, we did not formally examine patients' sensory deficits, which 457 could be a component of further study. Second, here we examined kinematics in 2D with full arm support. 458 Fully evaluating post-stroke motor control, however, would need to examine kinematics in all three 459 dimensions. 3D movement control may contain features not prominent in horizontal planar movement, such 460 as the engagement of more muscles, a wider range of joint configurations, and dealing with the effects of 461 weight bearing. For the latter part, especially, it may be worthwhile to systematically examine the 462 relationship between FM-UE and kinematics under intermediate amounts of arm support rather than either 463 full or none in order to properly map the interplay between synergies, strength, and kinematics.

\section{Conclusion}

465 Here we show that there is a dissociation between loss of reaching dexterity and presence of abnormal 466 muscle synergies in the contralesional arm after stroke; two prominent and characteristic signs of 467 hemiparesis. To dissect these two signs, we designed a reaching task in which we isolated arm dexterity 468 from synergy by providing weight support, and we separately assessed abnormal synergies using the Fugl469 Meyer score for the Upper Extremity (FM-UE). Across patients, abnormal muscle synergies were not 
medRxiv preprint doi: https://doi.org/10.1101/2021.07.21.21260448; this version posted August 26, 2021. The copyright holder for this preprint (which was not certified by peer review) is the author/funder, who has granted medRxiv a license to display the preprint in perpetuity.

All rights reserved. No reuse allowed without permission.

correlated with loss of arm dexterity. Critically, there was a large difference in dexterity deficits between subacute and chronic patients matched for similar levels of abnormal synergy: patients in the chronic stage had more normal planar reaching trajectories even with worse FM-UE scores. These dissociations suggest that abnormal synergies and dexterity deficits reflect distinct components of hemiparesis, perhaps attributable to damage to separable systems. Finally, we found that FM-UE scores correlated with arm weakness. This suggests that both synergies and weakness are independent of arm dexterity loss. In short, our findings suggest that recovery from hemiparesis does not proceed uniformly across its components. Stroke rehabilitation should be tailored for each patient based on their specific component deficits; a form

478 of behavioral precision medicine.

\section{Acknowledgements}

This work has been supported by NIH (grant 5R01HD053793) and the Sheikh Khalifa Stroke Institute. We would like to thank Jeff Goldsmith, Jing Xu, Adrian Haith, and Juan Camilo Cortes for helpful discussions, Amanda Therrien for help with experiment software, as well as Kahori Kita and Kendra Cherry-Allen for 483 help with assessments.

\section{Bibliography}

Ada, Louise, Nicholas O’Dwyer, Julie Green, William Yeo, and Peter Neilson. 1996. "The Nature of the Loss of Strength and Dexterity in the Upper Limb Following Stroke." Movement Control: A Southern Hemisphere Perspective 15 (5): 671-87. https://doi.org/10.1016/0167-9457(96)000152.

Beer, Randall F, Julius PA Dewald, Michelle L Dawson, and W Zev Rymer. 2004. "Target-Dependent Differences between Free and Constrained Arm Movements in Chronic Hemiparesis." Experimental Brain Research 156 (4): 458-70.

Beer, Randall F, Michael D Ellis, Bradley G Holubar, and Julius PA Dewald. 2007. "Impact of Gravity Loading on Post-stroke Reaching and Its Relationship to Weakness." Muscle \& Nerve: Official Journal of the American Association of Electrodiagnostic Medicine 36 (2): 242-50.

Bernhardt, Julie, Kathryn S Hayward, Gert Kwakkel, Nick S Ward, Steven L Wolf, Karen Borschmann, John W Krakauer, Lara A Boyd, S Thomas Carmichael, and Dale Corbett. 2017. "Agreed Definitions and a Shared Vision for New Standards in Stroke Recovery Research: The Stroke Recovery and Rehabilitation Roundtable Taskforce.” International Journal of Stroke 12 (5): 444 50.

Bohannon, Richard W. 1990. "Shoulder Position Influences Elbow Extension Force in Healthy Individuals." Journal of Orthopaedic \& Sports Physical Therapy 12 (3): 111-14.

Bourbonnais, Daniel, Sharyn Vanden Noven, Kathleen M Carey, and William Z Rymer. 1989. "Abnormal Spatial Patterns of Elbow Muscle Activation in Hemiparetic Human Subjects." Brain 112 (1): 85-102.

Brunnstrom, Signe. 1966. "Motor Testing Procedures in Hemiplegia: Based on Sequential Recovery Stages." Physical Therapy 46 (4): 357-75. 
medRxiv preprint doi: https://doi.org/10.1101/2021.07.21.21260448; this version posted August 26, 2021. The copyright holder for this preprint (which was not certified by peer review) is the author/funder, who has granted medRxiv a license to display the preprint in perpetuity. All rights reserved. No reuse allowed without permission.

Cheney, Paul D, Eberhard E Fetz, and Klaus Mewes. 1991. "Neural Mechanisms Underlying Corticospinal and Rubrospinal Control of Limb Movements." Progress in Brain Research 87: 213-52.

Chollet, François, Jean Tardy, Jean-François Albucher, Claire Thalamas, Emilie Berard, Catherine Lamy, Yannick Bejot, Sandrine Deltour, Assia Jaillard, and Philippe Niclot. 2011. "Fluoxetine for Motor Recovery after Acute Ischaemic Stroke (FLAME): A Randomised Placebo-Controlled Trial." The Lancet Neurology 10 (2): 123-30.

Cortes, Juan C., Jeff Goldsmith, Michelle D. Harran, Jing Xu, Nathan Kim, Heidi M. Schambra, Andreas R. Luft, Pablo Celnik, John W. Krakauer, and Tomoko Kitago. 2017. "A Short and Distinct Time Window for Recovery of Arm Motor Control Early After Stroke Revealed With a Global Measure of Trajectory Kinematics." Neurorehabilitation and Neural Repair 31 (6): 552-60. https://doi.org/10.1177/1545968317697034.

Crisostomo, Edgardo A., Pamela W. Duncan, Martha Propst, Deborah V. Dawson, and James N. Davis. 1988. "Evidence That Amphetamine with Physical Therapy Promotes Recovery of Motor Function in Stroke Patients." Annals of Neurology 23 (1): 94-97. https://doi.org/10.1002/ana.410230117.

Davidson, Adam G, and John A Buford. 2004. "Motor Outputs from the Primate Reticular Formation to Shoulder Muscles as Revealed by Stimulus-Triggered Averaging." Journal of Neurophysiology 92 (1): 83-95.

Davidson, Adam G, Marc H Schieber, and John A Buford. 2007. "Bilateral Spike-Triggered Average Effects in Arm and Shoulder Muscles from the Monkey Pontomedullary Reticular Formation." Journal of Neuroscience 27 (30): 8053-58.

Dewald, Julius PA, Patrick S Pope, Joseph D Given, Thomas S Buchanan, and W Zev Rymer. 1995. "Abnormal Muscle Coactivation Patterns during Isometric Torque Generation at the Elbow and Shoulder in Hemiparetic Subjects." Brain 118 (2): 495-510.

Duncan, Pamela, Stephanie Studenski, Lorie Richards, Steven Gollub, Lai Sue Min, Reker Dean, Perera Subashan, et al. 2003. "Randomized Clinical Trial of Therapeutic Exercise in Subacute Stroke." Stroke 34 (9): 2173-80. https://doi.org/10.1161/01.STR.0000083699.95351.F2.

Duncan, Pamela W, Larry B Goldstein, David Matchar, George W Divine, and John Feussner. 1992. "Measurement of Motor Recovery after Stroke. Outcome Assessment and Sample Size Requirements." Stroke 23 (8): 1084-89.

Duncan, Pamela W, Sue Min Lai, and John Keighley. 2000. "Defining Post-Stroke Recovery: Implications for Design and Interpretation of Drug Trials." Neuropharmacology 39 (5): 835-41.

Efron, Bradley, and Robert J Tibshirani. 1994. An Introduction to the Bootstrap. CRC press.

Fasoli, Susan E., Hermano I. Krebs, Joel Stein, Walter R. Frontera, and Neville Hogan. 2003. "Effects of Robotic Therapy on Motor Impairment and Recovery in Chronic Stroke." Archives of Physical Medicine and Rehabilitation 84 (4): 477-82. https://doi.org/10.1053/apmr.2003.50110.

Feys Hilde M., De Weerdt Willy J., Selz Beat E., Cox Steck Gail A., Spichiger Ruth, Vereeck Luc E., Putman Koen D., and Van Hoydonck Gustaaf A. 1998. "Effect of a Therapeutic Intervention for the Hemiplegic Upper Limb in the Acute Phase After Stroke." Stroke 29 (4): 785-92. https://doi.org/10.1161/01.STR.29.4.785.

Francisco, Gerard, John Chae, Harmeen Chawla, Steven Kirshblum, Richard Zorowitz, Gerald Lewis, and Schone Pang. 1998. "Electromyogram-Triggered Neuromuscular Stimulation for Improving the Arm Function of Acute Stroke Survivors: A Randomized Pilot Study." Archives of Physical Medicine and Rehabilitation 79 (5): 570-75.

Fugl-Meyer, Axel R, L Jääskö, Ingegerd Leyman, Sigyn Olsson, and Solveig Steglind. 1975. "The PostStroke Hemiplegic Patient. 1. a Method for Evaluation of Physical Performance." Scandinavian Journal of Rehabilitation Medicine 7 (1): 13-31.

Glover, Isabel S, and Stuart N Baker. 2020. "Cortical, Corticospinal, and Reticulospinal Contributions to Strength Training." Journal of Neuroscience 40 (30): 5820-32. 
medRxiv preprint doi: https://doi.org/10.1101/2021.07.21.21260448; this version posted August 26, 2021. The copyright holder for this preprint (which was not certified by peer review) is the author/funder, who has granted medRxiv a license to display the preprint in perpetuity. All rights reserved. No reuse allowed without permission.

Goldsmith, Jeff, and Tomoko Kitago. 2016. “Assessing Systematic Effects of Stroke on Motorcontrol by Using Hierarchical Function-on-Scalar Regression.” Journal of the Royal Statistical Society. Series C, Applied Statistics 65 (2): 215.

Haaland, Kathleen Y, Jillian L Prestopnik, Robert T Knight, and Roland R Lee. 2004. "Hemispheric Asymmetries for Kinematic and Positional Aspects of Reaching." Brain 127 (5): 1145-58.

Hughlings Jackson, John. 1884. "Evolution and Dissolution of the Nervous System." Selected Writings of John Hughlings-Jackson 2: 45-75.

Johnson, Catherine Owens, Minh Nguyen, Gregory A Roth, Emma Nichols, Tahiya Alam, Degu Abate, Foad Abd-Allah, Ahmed Abdelalim, Haftom Niguse Abraha, and Niveen ME Abu-Rmeileh. 2019. "Global, Regional, and National Burden of Stroke, 1990-2016: A Systematic Analysis for the Global Burden of Disease Study 2016." The Lancet Neurology 18 (5): 439-58.

Jørgensen, Henrik S., Hirofumi Nakayama, Hans O. Raaschou, Jørgen Vive-Larsen, Mogens Støier, and Tom S. Olsen. 1995. "Outcome and Time Course of Recovery in Stroke. Part II: Time Course of Recovery. The Copenhagen Stroke Study." Archives of Physical Medicine and Rehabilitation 76 (5): 406-12. https://doi.org/10.1016/S0003-9993(95)80568-0.

Kitago, Tomoko, Jeff Goldsmith, Michelle Harran, Leslie Kane, Jessica Berard, Sylvia Huang, Sophia L Ryan, Pietro Mazzoni, John W Krakauer, and Vincent S Huang. 2015. "Robotic Therapy for Chronic Stroke: General Recovery of Impairment or Improved Task-Specific Skill?” Journal of Neurophysiology 114 (3): 1885-94.

Krakauer, John W, and S Thomas Carmichael. 2017. Broken Movement: The Neurobiology of Motor Recovery after Stroke. MIT Press.

Kwakkel, Gert, Caroline Winters, Erwin EH Van Wegen, Rinske HM Nijland, Annette AA Van Kuijk, Anne Visser-Meily, Jurriaan De Groot, Erwin De Vlugt, J Hans Arendzen, and Alexander CH Geurts. 2016. "Effects of Unilateral Upper Limb Training in Two Distinct Prognostic Groups Early after Stroke: The EXPLICIT-Stroke Randomized Clinical Trial.” Neurorehabilitation and Neural Repair 30 (9): 804-16.

Lo, Albert C, Peter D Guarino, Lorie G Richards, Jodie K Haselkorn, George F Wittenberg, Daniel G Federman, Robert J Ringer, Todd H Wagner, Hermano I Krebs, and Bruce T Volpe. 2010. "Robot-Assisted Therapy for Long-Term Upper-Limb Impairment after Stroke." New England Journal of Medicine 362 (19): 1772-83.

Lum, Peter S., Charles G. Burgar, Peggy C. Shor, Matra Majmundar, and Machiel Van der Loos. 2002. "Robot-Assisted Movement Training Compared with Conventional Therapy Techniques for the Rehabilitation of Upper-Limb Motor Function after Stroke." Archives of Physical Medicine and Rehabilitation 83 (7): 952-59. https://doi.org/10.1053/apmr.2001.33101.

McPherson, Jacob G, Albert Chen, Michael D Ellis, Jun Yao, CJ Heckman, and Julius PA Dewald. 2018. "Progressive Recruitment of Contralesional Cortico-reticulospinal Pathways Drives Motor Impairment Post Stroke." The Journal of Physiology 596 (7): 1211-25.

Nakayama, Hirofumi, Henrik Stig Jørgensen, Hans Otto Raaschou, and Tom Skyhøj Olsen. 1994. "Recovery of Upper Extremity Function in Stroke Patients: The Copenhagen Stroke Study." Archives of Physical Medicine and Rehabilitation 75 (4): 394-98.

Nasreddine, Ziad S, Natalie A Phillips, Valérie Bédirian, Simon Charbonneau, Victor Whitehead, Isabelle Collin, Jeffrey L Cummings, and Howard Chertkow. 2005. "The Montreal Cognitive Assessment, MoCA: A Brief Screening Tool for Mild Cognitive Impairment." Journal of the American Geriatrics Society 53 (4): 695-99.

Niemi M L, Laaksonen R, Kotila M, and Waltimo O. 1988. "Quality of Life 4 Years after Stroke.” Stroke 19 (9): 1101-7. https://doi.org/10.1161/01.STR.19.9.1101.

Parker, VM, DT Wade, and R Langton Hewer. 1986. "Loss of Arm Function after Stroke: Measurement, Frequency, and Recovery." International Rehabilitation Medicine 8 (2): 69-73.

Pearce, J M S. 2004. "Positive and Negative Cerebral Symptoms: The Roles of Russell Reynolds and Hughlings Jackson.” Journal of Neurology, Neurosurgery \&amp; Psychiatry 75 (8): 1148. https://doi.org/10.1136/jnnp.2004.038422. 
medRxiv preprint doi: https://doi.org/10.1101/2021.07.21.21260448; this version posted August 26, 2021. The copyright holder for this preprint (which was not certified by peer review) is the author/funder, who has granted medRxiv a license to display the preprint in perpetuity. All rights reserved. No reuse allowed without permission.

608

609

610

611

612

613

614

615

616

617

618

619

620

621

622

623

624

625

626

627

628

629

630

631

632

633

634

635

636

637

638

639

640

641

642

643

644

645

646

647

648

649

650

651

652

653

654

655

656

Rabadi, Meheroz H., and Freny M. Rabadi. 2006. "Comparison of the Action Research Arm Test and the Fugl-Meyer Assessment as Measures of Upper-Extremity Motor Weakness After Stroke." Archives of Physical Medicine and Rehabilitation 87 (7): 962-66. https://doi.org/10.1016/j.apmr.2006.02.036.

Rathore, Saif S, Albert R Hinn, Lawton S Cooper, Herman A Tyroler, and Wayne D Rosamond. 2002. "Characterization of Incident Stroke Signs and Symptoms: Findings from the Atherosclerosis Risk in Communities Study." Stroke 33 (11): 2718-21.

Riddle, C. Nicholas, and Stuart N. Baker. 2010. "Convergence of Pyramidal and Medial Brain Stem Descending Pathways Onto Macaque Cervical Spinal Interneurons.” Journal of Neurophysiology 103 (5): 2821-32. https://doi.org/10.1152/jn.00491.2009.

Riddle, C Nicholas, Steve A Edgley, and Stuart N Baker. 2009. "Direct and Indirect Connections with Upper Limb Motoneurons from the Primate Reticulospinal Tract." Journal of Neuroscience 29 (15): 4993-99.

Schambra, Heidi M, Jing Xu, Meret Branscheidt, Martin Lindquist, Jasim Uddin, Levke Steiner, Benjamin Hertler, Nathan Kim, Jessica Berard, and Michelle D Harran. 2019. "Differential Poststroke Motor Recovery in an Arm versus Hand Muscle in the Absence of Motor Evoked Potentials." Neurorehabilitation and Neural Repair 33 (7): 568-80.

Schepens, Bénédicte, and Trevor Drew. 2006. "Descending Signals from the Pontomedullary Reticular Formation Are Bilateral, Asymmetric, and Gated during Reaching Movements in the Cat." Journal of Neurophysiology 96 (5): 2229-52.

Stinear, Cathy. 2010. "Prediction of Recovery of Motor Function after Stroke." The Lancet Neurology 9 (12): 1228-32. https://doi.org/10.1016/S1474-4422(10)70247-7.

Stinear, Cathy M., Winston D. Byblow, Suzanne J. Ackerley, P. Alan Barber, and Marie-Claire Smith. 2017. "Predicting Recovery Potential for Individual Stroke Patients Increases Rehabilitation Efficiency." Stroke 48 (4): 1011-19. https://doi.org/10.1161/STROKEAHA.116.015790.

Sukal, Theresa M, Michael D Ellis, and Julius PA Dewald. 2007. "Shoulder Abduction-Induced Reductions in Reaching Work Area Following Hemiparetic Stroke: Neuroscientific Implications." Experimental Brain Research 183 (2): 215-23.

Twitchell, Thomas E. 1951. "The Restoration of Motor Function Following Hemiplegia in Man.” Brain 74 (4): 443-80.

Tyryshkin, Kathrin, Angela M Coderre, Janice I Glasgow, Troy M Herter, Stephen D Bagg, Sean P Dukelow, and Stephen H Scott. 2014. "A Robotic Object Hitting Task to Quantify Sensorimotor Impairments in Participants with Stroke.” Journal of Neuroengineering and Rehabilitation 11 (1): 47.

Van der Lee, Johanna H, Robert C Wagenaar, Gustaaf J Lankhorst, Tanneke W Vogelaar, Walter L Devillé, and Lex M Bouter. 1999. "Forced Use of the Upper Extremity in Chronic Stroke Patients: Results from a Single-Blind Randomized Clinical Trial.” Stroke 30 (11): 2369-75.

Viitanen, Matti, KS Fugl-Meyer, Birgitta Bernspång, and Axel R Fugl-Meyer. 1988. "Life Satisfaction in Long-Term Survivors after Stroke.” Scandinavian Journal of Rehabilitation Medicine 20 (1): 1724.

Winstein, CJ, and PS Pohl. 1995. "Effects of Unilateral Brain Damage on the Control of Goal-Directed Hand Movements." Experimental Brain Research 105 (1): 163-74.

Xu, Jing, Naveed Ejaz, Benjamin Hertler, Meret Branscheidt, Mario Widmer, Andreia V Faria, Michelle D Harran, Juan C Cortes, Nathan Kim, and Pablo A Celnik. 2017. "Separable Systems for Recovery of Finger Strength and Control after Stroke." Journal of Neurophysiology 118 (2): 1151-63.

Zaaimi, Boubker, Steve A Edgley, Demetris S Soteropoulos, and Stuart N Baker. 2012. "Changes in Descending Motor Pathway Connectivity after Corticospinal Tract Lesion in Macaque Monkey." Brain 135 (7): 2277-89. 
medRxiv preprint doi: https://doi.org/10.1101/2021.07.21.21260448; this version posted August 26, 2021. The copyright holder for this preprint (which was not certified by peer review) is the author/funder, who has granted medRxiv a license to display the preprint in perpetuity.

All rights reserved. No reuse allowed without permission. Strength, Sensation, Spasticity and Joint Individuation Relate to the Reaching Deficits of People with Chronic Hemiparesis?" Brain 127 (5): 1035-46. 